\title{
Erratum to: Laparoscopy-to-laparotomy quotient in obstetrics and gynecology residency programs
}

\author{
M. Sami Walid • Richard L. Heaton
}

Published online: 16 November 2010

(C) Springer-Verlag 2010

\section{Erratum to: Arch Gynecol Obstet}

DOI 10.1007/s00404-010-1477-2

The original version of the article unfortunately contained some errors in the captions of Table 2 and Fig. 3.

The correct captions are as follows:

Table 2 OBGYN programs with LPQ $\geq 1$

Fig. 3 The relationship between laparoscopy, laparotomy and LPQ

The online version of the original article can be found under doi:10.1007/s00404-010-1477-2.

M. Sami Walid $(\bowtie)$

Medical Center of Central Georgia,

840 Pine Street, Suite 880, Macon, GA 31201, USA

e-mail: mswalid@yahoo.com

R. L. Heaton

Heart of Georgia Women's Center,

209 Green Street, Warner Robins, GA 31099, USA

e-mail: riclheaton@yahoo.com 